\title{
DYADS AND TRIADS AT 35,000 FEET: FACTORS AFFECTING GROUP PROCESS AND AIRCREW PERFORMANCE ${ }^{1}$
}

\author{
Dr. H. Clayton Foushee \\ NASA-Ames Research Center
}

\section{INTRODUCTION}

The large percentage of aircraft incidents and accidents attributed to "human error" has focused increasing attention upon the performance characteristics of the individual pilot. Traditionally, human factors specialists have channeled their research energies toward exploration of the human information processing and perceptual aspects of the pilot's job with the important goal of designing equipment best suited to the characteristics of the human operator. Human factors psychologists and aeronautical engineers have continually refined designs on the basis of an improved understanding of human operators to the extent that each new generation of aircraft not only promises better performance, but also reduced pilot workload. Despite this effort, about 65 percent of all accidents continue to fall into the human error category.

As a direct result of the limitations and imperfections of individual humans, multipiloted aircraft cockpits were designed to ensure needed redundancy. Yet, this redundancy has failed to provide an adequate margin of safety in some cases. It has failed too often because captains have not heeded the warnings of other crewmembers. It has failed because crewmembers who possessed adequate information have for some reason not provided it to others. In fact, a review and analysis of jet transport accidents worldwide during the period from 1968 to 1976 (Cooper, White, \& Lauber, 1979) revealed more than 60 in which breakdowns of the crew performance process played a significant role. Although individual pilot performance remains an important research topic, these occurrences suggest that more attention need be placed upon crew performance and the factors which affect crew coordination.

Webster's New Collegiate Dictionary (1961) defines cockpit as, "a region noted for many conflicts." Although this definition does not specifically apply to aircraft cockpits, we have found it interesting to note how often interpersonal phenomena can affect air transport operations. Since the cockpit crew is a highly structured small group, a number of socio-psychological, personality, and group process variables are relevant to crew effectiveness. The complexities of the operational environment, aircraft systems, and the sheer volume of information that must be processed (often in brief periods of time), mandate highly coordinated team performance. Rigorous company hiring practices, employment conditions, and regulations requiring frequent checking and retraining have together assured that each crewmember is a highly skilled professional. However, in situations where a high level of teamwork is required, the individual skills of

\footnotetext{
1 EDITORS' NOTE: This paper orginally appeared in Americen Psychologiat, 99, August, 1984. Because it diacuses many of the theoretical and practical issues related to CRM training, it is reprinted here.
} 
team members are often not enough to guarantee satisfactory outcomes in all situations. Jones (1974) illustrated this assertion in a study of professional athletic teams. Teams with better athletes seem to win more often, but the strength of this relationship is dependent on the extent to which the particular sport requires teamwork. Jones found that $90 \%$ of baseball team effectiveness was predictable from the skills of individual team members, while only $35 \%$ was predicted by this factor in basketball teams. In explaining this result, the author notes that basketball is critically dependent upon personal relations and teamwork.

Despite the fact that thousands of studies of group performance have implicated many variables (Hare, 1972; McGrath \& Altman, 1966), group performance problems have received relatively little attention in the aviation research and training communities. However, awareness of these problems is gradually increasing. Following an airline accident in 1978 , in which the crew was preoccupied by a minor mechanical malfunction and allowed the aircraft to run out of fuel, the U. S. National Transportation Safety Board, a government organization whose major responsibility is the investigation of transportation mishaps, stated in their report of the accident (NTSB, 1979b):

The Safety Board believes that this accident exemplifies a recurring problem--a breakdown in cockpit management and teamwork during a situation involving malfunctions of aircraft systems in flight. To combat this problem, responsibilities must be divided among members of the flightcrew while a malfunction is being resolved. . . .

Admittedly, the stature of a captain and his management style may exert subtle pressure on his crew to conform to his way of thinking. It may hinder interaction and adequate monitoring and force another crew member to yield his right to express an opinion. (pp. 26-27)

In 1982, subsequent to an accident in which the aircraft struck a bridge shortly after takeoff and crashed into the Potomac River, the Board (NTSB, 1982) ruled that the captain of that aircraft did not react to the copilot's repeated, subtle advisories that all was not normal during the takeoff. Moreover, the Board implied that the copilot's lack of assertiveness (possibly induced by the inherent role structure of the cockpit) may have been a causal factor in recommending that pilot training include "considerations for command decision, resource management, role performance, and assertiveness." (pp. 6768)

It is unfortunate, in light of the increasing awareness of group performance variables in air transport operations and the volume of research dealing with group function, that we still know little about why some groups perform better than others. There are at least two principal reasons for this apparent shortcoming. First, it is difficult to assimilate the sheer number of variables that can potentially affect group processes. This poses methodological difficulties that have forced those concerned with group performance to attempt to isolate a few variables at a time in any given experiment. Thus, the literature is characterized by a collection of seemingly inconsistent results, each study examining the effects of a different subset of relevant factors. The second point concerns the fact that most of the closely controlled studies have taken place in 
laboratory settings. Given the obvious difficulty of maintaining experimental control in the real world, we have relied upon more comfortable environs. As Helmreich (1975) has noted, we may have sterilized our research through an over-reliance on the laboratory, the result being that organizational decision-makers in the aviation community and elsewhere have been less likely to concentrate on solutions to group performance problems. They have instead focused on the more manageable problem of what to do about individual performers.

It would appear that a partial explanation of the inconsistency and lack of robustness of the literature is inherent in the research methodology itself. The practice of looking at isolated variables has contributed to a state of affairs where factors that make big differences in group behavior are held constant because they are neither easily controlled nor manipulated in the laboratory and where potentially important intervening variables are often ignored. As Hackman and Morris (1975) have noted, most studies examine only parts of a complicated phenomenon such as the contribution of input factors (e.g. member skills, attitudes, and personality) to the outcome factor (e.g. group productivity), ignoring that it may be the process of group interaction that holds the key to understanding group performance. For example, a study examining the effect of group member personalities (an input) on performance (the output) might discover meager or non-existent statistical associations, and as a result one may infer that such profiles are unrelated to group performance. Yet, this inference may be entirely incorrect. It is possible that the same personality profiles would be strongly related to intervening process variables such as communication patterns or other interactional behavior. These process variables, in turn, might be related to the outcome variable. Thus, mediating variables might account for most of the relationship, but have often been overlooked.

The group interactional process has been alternatively viewed as both a positive and negative feature of tasks performed by groups instead of by individuals. Hackman and Morris (1975) have noted that, "It is tempting to conclude that the 'group effectiveness problem' will not be solved in the foreseeable future, and to recommend to decisionmakers that in the meantime they use groups as infrequently as possible." Steiner (1972) characterizes group performance in terms of "process-loss", which inhibits the group from reaching its potential. Others (e.g. Hackman \& Morris, 1975) propose that interaction among group members performs the valuable function of preventing errors that may occur if individuals perform the task in isolation; and that despite the inefficiency of the process, it is acceptable in any situation where error-free performance is necessary. This notion, that substituting groups for individuals results in error-free performance through redundancy, has been challenged. Janis (1972) proposes that this process is frequently compromised by "groupthink" in close-knit groups, a phenomenon characterized by a marked decrease in the exchange of discrepant or unsettling information, even when it is forced to the attention of members.

In the sections that follow, I will review some of the input, process, and outcome variables in the small group performance situation faced by aircraft flightcrews. A strong emphasis is placed upon the group process. Hackman and Morris (1975) have argued eloquently for this approach, and their work has been a stimulus for this application. More specifically, the focus here will be upon links between personality or interpersonal styles of leadership as input variables; communication patterns and crew 
coordination as group process variables; and upon operational errors, incidents, and accidents as outcome variables. A concluding section reviews some of the ways that the air carrier industry is now addressing group performance problems.

In some sense, this application of small group theory to the flight deck is facilitated by the fact that we are dealing with groups operating within a tightly prescribed operating environment (relative to many group tasks) and with a clearly defined role structure (captain, first officer, and second officer or flight engineer). Thus, certain input factors such as task characteristics, reward structure, position power, stress levels, etc. are relatively constant within this particular type of group.

\section{INPUT VARIABLES AND THE FLIGHTCREW PROCESS}

There are numerous input conditions that affect the group interactional process, but member personality characteristics and individual differences have probably received the most attention. Moreover, organizations concerned with pilot selection have utilized personality inventories for years, but as Helmreich has noted (In Cooper, White, \& Lauber, 1979), such efforts have usually been oriented toward the screening of pathology.

In the group research domain, leadership studies have concentrated heavily upon the identification of "profiles" or personality characteristics which are associated with successful leadership. Fiedler (1967) and coworkers undertook an ambitious program to identify those profiles most pertinent to successful leadership. It is impossible to detail the findings of this program here, but briefly stated, Fiedler identified two basic types of leadership profiles, task-oriented and relationship-oriented, which were related to group performance in a complicated interactive fashion. Not surprisingly, the type of leadership. style that was most effective was heavily dependent on the type of group and the task with which the group was charged. In groups with highly structured tasks and powerful leader positions, such as the cockpit crew, task-oriented leaders performed better as long as interpersonal relationships within the group remained relatively good. Relationship-oriented leaders performed better in groups where leader-member relations where relatively poor. These data are interesting, but appear intuitively paradoxical. It would seem logical to posit that relationship-oriented leaders, over time, would more often find themselves in situations characterized by good interpersonal relations; whereas task-oriented leaders would more often find themselves in situations where leadermember relations are poor. While the Fiedler data may be valid for the situations tested, it could be argued that relationship-oriented leaders less frequently find themselves in situations where leader-member relations are poor. However, there are apparently no data on the relative frequencies of these patterns.

Another characteristic of this approach is that task-orientation and relationshiporientation profiles are usually treated as mutually exclusive patterns. Yet, a substantial amount of research dealing with these two global dimensions would seem to indicate that this is not the case (e.g. Blake \& Mouton, 1978; Spence \& Helmreich, 1978). Spence and Helmreich (1978) have conducted research that argues persuasively for the idea that instrumentality, or goal orientation, and expressivity, or interpersonal orientation, are 
orthogonal. Blake and Mouton (1978) suggest that the most effective style of leadership or management is associated with a profile that encompasses both sets of characteristics. Thus, there is increasing interest in the notion that both task orientation and interpersonal orientation are necessary for the effective management of all situations. The concept that these two sets of attributes can be present in one individual and balanced depending on the situation is perhaps a more appealing concept for decisionmakers than theories that suggest an inverse relationship between the two. Previous approaches (e.g. Fiedler, 1967) have speculated that the decision-maker should assign managers to situations more in keeping with their particular leadership style. Unfortunately, this is not practical in many environments, but perhaps even more problematic is the fact that most management situations are dynamic and in constant evolution.

With respect to the flight deck, as in most performance situations, it has usually been assumed that goal orientation is strongly related to performance and that group orientation is essentially unrelated. However, Helmreich (1982) has presented data which would seem to indicate otherwise. In a study of air carrier pilots, both goal and group orientations were significant predictors of the group process variable of crew coordination.

As previously suggested, the incident and accident record has also implicated the lack of an effective interpersonal orientation as a cause of breakdowns in the group process variable of information exchange. Subordinate crewmembers complain that captains are at times so insensitive and intimidating that they hesitate to speak up even in potentially dangerous situations. We have identified the extent of this problem, in part, through a confidential data base, the Aviation Safety Reporting System (ASRS), which is a joint endeavor of NASA and the Federal Aviation Administration. This data base (which currently contains around 50,000 reports from pilots, air traffic controllers, and other members of the aviation community) has proven to be an invaluable tool for the identification of significant problem areas.

I recently reported an example of this type of behavior contained in a copilot report to ASRS (Foushee, 1982, p. 1063). Air traffic control had issued a speed restriction which was repeatedly ignored by the captain. After several attempts to convey the information, the captain responded by saying, "I'll do what I want." Air traffic control inquired as to why the aircraft had not been slowed, advised the crew that they had almost collided with another aircraft, and issued a new clearance which was also disregarded by the captain despite repeated clarification by the copilot. Following the last advisory from the copilot, the captain responded by telling the copilot to, "just look out the damn window."

The inherent danger of such situations is that subordinate crewmembers can become "conditioned" not to speak up after running into captains such as the one in the preceding report. Consistent behavior of this sort by captains (while not usually as blatant as in this example) may have contributed to the development of a normative pattern of what constitutes "appropriate copilot behavior," and there is a strong likelihood that this behavioral norm will transfer to situations where there is no reason for member effort to be suppressed. 
Another report from a copilot to ASRS (Foushee, 1982) illustrates this phenomenon. This report described a situation where air traffic control had instructed the flight to level off at 21,000 feet. As they reached their assigned altitude, the copilot noticed that the captain was climbing through it. The copilot mentioned it to the captain, "but not forcefully enough and he did not hear me." The copilot mentioned it again and pointed to the altimeter at which point the captain stopped the climb and descended back to the assigned altitude. Assigned alitudes are extremely critical in dense air traffic environments, and strict adherence to these altitudes is necessary because of the likelihood that other aircraft are assigned to adjacent airspace. Because of this, the copilot was extremely concerned about the incident and summed up the reasons for this occurrence in the following insightful manner:

The captain said he had misread his altimeter and thought he was $1000 \mathrm{ft}$. lower than he was. I believe the main factor involved here was my reluctance to correct the captain. This captain is very "approachable" and I had no real reason to hold back. It is just a bad habit that I think a lot of copilots have of double-checking everything before we say anything to the captain. (p. 1063)

It should come as no great surprise that this situation can produce, and has produced, disastrous consequences. In a 1979 crash of a north-eastern commuter carrier (NTSB, 1980), the first officer failed to take control of the aircraft when the captain apparently became incapacitated. The captain was a company vice-president and the first officer was a recently hired pilot still on probation. The captain, according to reports, was a gruff personality and was observed to be visibly upset on the day of the accident. Further, this captain apparently had a history of not acknowledging cockpit communications. Clearly, the group dynamics of that particular situation were not conducive to the first officer's assumption of control. It would appear that had the first officer not been intimidated, the accident might not have occurred. In another accident (N'TSB, 1979a), a twin-jet slid off the end of the runway after crossing the outer marker approximately 60 knots over desired speed. Although the captain was apparently unaware of the excessive speed, evidence indicates that the first officer knew, but could only muster a sheepish comment about the possible presence of a tail-wind.

It is reasonable to assume that the development of a strong group norm of shared responsibility will increase the probability that subordinate crewmembers will function more effectively in critical instances. Obviously, the captain's leadership style is an important component for the establishment of such a norm, but it is by no means the only component. Apparently, the reluctance to question captains or assume control is not an isolated problem. In an investigation conducted by Harper, Kidera, and Cullen (1971) at a major air carrier, captains feigned subtle incapacitation at a predetermined point during final approach in simulator trials characterized by poor weather and visibility. In that study, approximately twenty-five percent of these simulated flights "hit the ground" because, for some reason, the first officers did not take control.

While there are no carefully controlled studies of the effects of leader and member personality profiles, such as instrumentality and expressiveness, on the flightcrew interactional process (although Helmreich, Note 1, provides some evidence), incident and accident data suggest that such profiles are important predictors of certain group process variables in the aviation environment. Research now in progress in our laboratory will 
hopefully shed more light on these relationships.

\section{FLIGHTCREW PROCESS VARIABLES AND PERFORMANCE}

Researchers in the aviation environment are perhaps more fortunate than many of our laboratory research colleagues. The rapid advancement of simulator technology has provided an ideal laboratory for the study of group process variables. It is now feasible to realistically simulate virtually every aspect of the aircraft operational environment (complete with realistic auditory, visual, and motion cues) to the point where actual trips can be "flown" in a simulator, and these "flights" are almost indistinguishable from those in the airplane. Due to the high degree of simulator fidelity, it is possible to conduct controlled studies of group process variables with almost complete confidence that the results generated in the simulator are strongly (if not completely) representative of the real world (Lauber \& Foushee, 1981). Moreover, the simulator allows the study of situations that are too dangerous to perform in an actual aircraft.

The best example of this use of simulation was conducted by H. P. Ruffell Smith (1979) in a study which was not originally designed as an investigation of group process, but which provided strong evidence for the importance of the group performance dimension. In that study, B-747 crews were asked to fly a highly realistic simulated flight from New York to London. Because of an oil-pressure problem, the crew was forced to shut down an engine. Since the trip to London could not be completed with a failed engine, the crew had to decide where to land the airplane, and the decision was further compounded by a hydraulic system failure, poor weather, less than ideal air traffic control, and a cabin crewmember who consistently requested assistance from the cockpit crew at inopportune moments. The Ruffell Smith (1979) study allowed the examination of flightcrew performance in a completely controlled setting, and there were marked variations in the performance of the crews. Perhaps the most salient aspect of this flight simulation study was the finding that the majority of problems was related to breakdowns in crew coordination, not to a lack of technical knowledge and skill. "High error" crews experienced difficulties in the areas of communication, crew interaction, and integration. For example, some of the more serious errors occurred when the performance of an individual crewmember was interrupted by demands from other crewmembers. Other performance deficiencies were associated with poor leadership and the failure of the flightcrew to exchange information in a timely fashion.

One of the most significant group process variables is reflected by the information flow within the group. The measurement of relational communication has been utilized over the years by a number of researchers in various paradigms (e.g. Bales, 1950; Mark, 1970). In studies that have examined the relationship between group process variables and performance effectiveness, careful analyses of the communications process have often proven fruitful. Lanzetta and Roby (1960) monitored and recorded all communications during a group performance task. Their study found that this particular measure of group interaction predicted task success better than such measures as member knowledge and skill. These authors suggest, in a quote that might as easily have come from one of the NTSB accident reports, that "the way the group 'utilizes' its resources and the procedures it employs for communicating essential information are as important, 
if not more important than 'knowledge' of the problem for determining its performance."

In a separate investigation designed to look at the group process, we (Foushee \& Manos, 1981) analyzed the cockpit voice recordings from the Ruffell Smith (1979) simulation study utilizing a technique adapted from Bales' (1950) interaction process analysis. Several interesting relationships emerged from the Foushee and Manos (1981) study. Overall, there was a tendency for crews who communicated less not to perform as well, but the type or quality of communication played an even more important role. There was a negative relationship between crewmember observations about flight status and errors related to the operation of aircraft systems. In short, when more information was transferred about aspects of flight status, fewer errors appeared which were related to such problems as mishandling of engines, hydraulic, and fuel systems, the misreading and missetting of instruments, the failure to use ice protection, and so forth.

It would appear that information exchange of this sort facilitates the development or coordination of strategies through the assurance that all members have access to the relevant information. However, there may be a negative side to the complete coordination or sharing of strategic plans unless group norms specifically allow for the processing of discrepant information. As Janis (1972) has pointed out, group processes often lead to situations where information discrepant with the group's strategic course of action is ignored or deemphasized, even when it is critically relevant. This can theoretically occur not only in groups where interpersonal relations are strained, but also in groups where there is too much agreement.

In other areas of information exchange, Foushee and Manos (1981) found a negative relationship between aircraft systems errors and acknowledgements to information provided by other crewmembers. In crews in which commands, inquiries, and observations were frequently acknowledged, these types of errors were less apparent. Acknowlegements were also related to fewer errors overall. It appeared that acknowledgements served the important function of validating that a certain piece of information had, in fact, been transferred. These types of communication also seemed to serve as reinforcements to the input of other crewmembers. This relationship suggests that communication patterns can serve to increase member effort and motivate further participation in the group process.

Commands were associated with a lower incidence of flying errors such as problems with power settings, neglect of speed limits, altitude deviations, and the lack of formal transfer of control between captain and first officer. Often communications of this type seem to assure the proper delegation of cockpit duties and facilitate coordination and planning. Yet, it should be noted that the overuse of imperative statements may have negative consequences. The use of commands provides a very good illustration of the effect of varying interpersonal styles. An identical piece of information can be related to other crewmembers in one of several different ways. For instance, a communication such as, "Ask air traffic control for a higher altitude," which would constitute a command; could also be relayed, "I think we should ask air traffic control for a higher altitude," an observation; or "Why don't we ask air traffic control for a higher altitude," an inquiry.

Foushee and Manos (1981) also found evidence for higher rates of response uncertainty, frustration or anger, embarrassment, and lower rates of agreement in crews 
who tended to make more errors. Despite the fact that these correlational data do not allow inferences of causation, it is safe to infer that discord related to the comission of errors, whether cause or effect, may be related to crew coordination deficiencies downstream.

In addition to the importance of communication style, the precision of communication plays a pivotal role. The ASRS data bank contains a number of incidents in which each pilot thought he or she knew what the other meant or intended to do when, in reality, they did not. One report to ASRS described a situation where a critical alarm went off in the cockpit followed by immediate diagnostic actions by the crew. Shortly thereafter the alarm silenced, leading the captain to believe that it was probably a false warning. After landing, the captain discovered that the circuit breaker for the alarm system had been pulled by the flight engineer, that it was not a false warning, and that the warning could have been potentially serious. The flight engineer stated that he had asked the captain if he wanted the warning inhibited, and since there was no reply, he assumed he was complying with the captain's wishes (Foushee, 1982, p. 1064).

In summary, there is strong evidence that the process of interaction is related to group performance in the cockpit environment. The reader should bear in mind that the results of the Ruffell Smith (1979), Foushee and Manos (1981), and other empirical studies in this area are based upon realistic flight simulations, where high levels of crew workload precipitated by carefully controlled events no doubt contributed to the crew performance problems reported herein. These levels of workload and stress are characteristic of many accident scenarios, but they are infrequently encountered in day to day operations. While the results of these studies may be disturbing to some, the remarkable overall safety of the system should be stressed. Fortunately, the problems discussed here rarely lead to accidents, which is a testament to overall system redundancy. It should be comforting to note that since accidents are so infrequent, they make terrible research criteria for judging crew performance, and it is a credit to the industry that the primary research and training concern is upon those aspects of performance which under some circumstances can have dramatic consequences. Attention is now turned to methods aimed at the facilitation of this process.

\section{ADDRESSING THE ISSUE}

Hackman and Morris (1975) suggest that the best way to effect meaningful change in group performance is to concentrate on input factors. Thus, it is proposed that group performance strategies can be made more task-appropriate by modifying the group's norms, that member effort and coordination can be increased by task redesign, and that the level and utilization of group member knowledge and skill can be improved by altering the composition of the group.

It was previously noted that the existence of group performance problems is becoming more salient to the air carrier industry. Several airlines, stimulated by this awareness, are beginning to address these issues in their training programs, and one company has made a substantial investment in a comprehensive program of "cockpit 
resource management" training for all of its pilots. The remainder of this discussion will focus on some of the techniques utilized in this program, and whether they may be expected to facilitate the group performance process.

\section{Altering Group Norms}

Much of the normative structure of professional pilots is well established, having evolved during a time when aviation was not routine and the dangers of flight were considerable. These conditions fostered, largely through self-selection processes, a pilot profile that has been characterized by Tom Wolfe (1979) as "the right stuff." An individual who typifies the right stuff is generally described as a highly goal-oriented, extremely self-reliant, macho, decisive sort; and it is clear that such a profile was functional, if not a prerequisite, for the job in the past. Some would argue that reliance upon others was negatively related to longevity in "the old days." While it is easy to visualize such individuals functioning effectively as fighter or test pilots, it is more difficult to view them as "good team players." In the past, airlines themselves did little to discourage captains from functioning in this manner. The 1952 guidelines for pilot proficiency checks at a major airline explicitly stated that the first officer should not correct errors made by the captain (H. W. Orlady, personnel communication). To this day, the Federal Aviation Regulations governing pilot qualifications deal almost exclusively with the acquisition and maintenance of individual pilot proficiency.

Despite the fact that the aviation environment has changed considerably, these norms are ubiquitous, and an attempt is being made to alter the normative structure of the flightcrew in some training programs. One method employed in an effort to correct certain ineffective task performance strategies, associated with excessive instrumentality, is the use of videotape feedback and diagnosis of task-specific behaviors. In one program, crews are asked to fly a full-mission simulation that is videotaped from start to finish. Following these simulated flights, crewmembers view the tape with an instructor and discuss such aspects of the group process as the effects of interpersonal styles, the appropriate delegation of responsibility, and how the role structure can inhibit the input of subordinate night crewmembers. From a theoretical standpoint, this approach may very well produce some tangible change. Duval and Wicklund (1972) in their theory of objective self awareness, found that self-focusing manipulations often force objective appraisals of oneself that may lead to attitude and behavior change. Anecdotal evidence from this program is suggestive of a positive impact, with crewmembers expressing surprise at their behavior during the videotaped flights.

Another prevalent technique within the industry is the use of seminars as a means of providing information aimed at altering the normative structure of flightcrews. These seminars are frequently offered as part of the training required for promotion from junior crewmember to captain. The philosophy underlying this approach, as well as other feedback approaches, is that heightened awareness will produce tangible behavior change. It is not presumed that the personality structures of individuals can be altered in a short period of time, but it is felt that the pilot socialization process has not generally produced patterns consistent with teamwork. Thus, it is argued that pilots are often not aware of how subtle factors can compromise group function. The educational content generally places a heavy emphasis on material related to the role of interpersonal styles and the effects of certain types of behavior on co-workers. Group exercises, 
personality assessment and feedback techniques, role-playing, case studies, and interpersonal encounter drills, are frequently employed.

It may surprise some to discover that these programs are proving to be popular in airlines that have implemented them, however, serious questions are usually raised as to their long-term effectiveness. It is probably true that these interventions provide shortterm insight, but long-term change is no doubt dependent on periodic exposure and reinforcement. Unfortunately, few organizations are providing their personnel with this type of training on a recurrent basis. Perhaps more disturbing is the dearth of research dealing with the evaluation or relative efficacy of such programs. Many principles, which are being "preached as the gospel" in such programs, are in need of further study.

\section{Increasing Member Effort and Coordination}

Raising individual member effort and coordinating these efforts is another means of increasing group productivity. One method suggests that restructuring the task, in a way that requires coordinated performance from all group members, will dictate increased member effort by necessity and produce normative change. Since flight training has traditionally emphasized individual skills, most pilots have had very little realistic experience with high workload or emergency situations that require teamwork. Moreover, equipment reliability and automation have rendered most flight tasks routine; high stress, emergency situations are relatively rare. Yet, as has been mentioned, this lack of experience may be a factor when crews are faced with non-routine situations; a view which is supported by the incident and accident record.

While it makes little sense to change substantively the task of flying most modern aircraft considering the remarkable safety record of the present system, it may be logical to restructure the training task. Many airlines are beginning to utilize a technique known as Line-Oriented Flight Training (LOFT; e.g. Lauber \& Foushee, 1981) in which crews fly a complete trip in a high-fidelity simulator. However, unlike the real world, LOFT scenarios are usually designed to include emergency situations which require the coordinated actions of all crewmembers for success. These flights occur in real time, and no intervention is made by the instructor regardless of the actions of the crew. LOFT is a learning experience in which errors are usually made. However, since effective group function in this environment is by definition the management of human error, LOFT provides highly effective crew coordination training. Just as it is necessary to practice landing skills in order to gain and maintain aircraft-handling proficiency, it is necessary to practice crew coordination skills in order to assure good flightcrew performance. LOFT provides the vehicle by which these skills, now recognized as important, are practiced and maintained. Some air carriers provide LOFT training every six or twelve months, and this approach may be a more viable way of producing long-term behavior change.

As Hackman and Morris (1975) suggest, the amount of effort group members put into a task is also heavily affected by the normative structure of the group. It has been noted that factors inherent in the role structure of the flightcrew, while necessary for the effective coordination of responsibilities, sometimes serve to decrease the effort expenditure of subordinate crewmembers. By changing the norms of the group and reinforcing the importance of coordinated performance, the malady some refer to as 
"captainitis" may begin to subside, and subordinate crewmembers may find it easier to have sufficient input into the group process. If these programs accomplish nothing else, they may have been beneficial by simply heightening awareness of the importance of leadership styles that encourage the input of all team members. By "legitimizing" this input or making it a part of the group's values, it is reasonable to expect some increase in member motivation, at least in the short-term.

\section{Changing Group Composition}

Altering the group's composition may be the most effective, and perhaps the most difficult of means for improving group effectiveness. Yet, it is an inescapable fact that successful group performance is heavily dependent upon the individual skills of members, and efforts aimed at the recruitment of qualified individuals has always been one of the favored means of producing the desired result. There is very little question that most airline pilots are highly skilled in the technical aspects of their job, but there is concern about their function as team members. In the United States, the labor pool is comprised heavily of pilots whose formative years were spent in high performance, single-seat, military aircraft. It has been suggested that pilots with this type of experience may bring an individualistic emphasis to the air carrier cockpit and that learning team member skills can only be accomplished slowly and painfully. One obvious solution would be the selection of individuals for the position of airline pilot who possess the skills associated with good leadership or team function.

For the airline industry, this approach has obvious drawbacks, at least in the nearterm. Clearly, it does not address the needs of the present pilot population, since past selection criteria have not encompassed these abilities. Helmreich (1982) has recently reported work with a new airline in which both instrumentality and expressiveness were among the desirable selection criteria for new pilots, but it is too soon to draw any inferences about the success of such selection practices.

\section{CONCLUDING THOUGHTS}

The most practical approach for most companies is to focus upon changing pilot attitudes and experiences in this domain. The techniques discussed above such as LOFT, seminars, and feedback are aimed at increasing the skills associated with group function in flight crewmembers through an increasing awareness of the importance of these factors. It should be stressed that this is neither a small task, nor is it a shortterm one. The open treatment of issues related to one's interpersonal competence can be, and has been, very anxiety-provoking for some individuals. No matter how well this type of training is conducted, certain people will be resistant to change provoking some critics of these programs to argue that the very individuals who need to improve will not benefit because they are the ones likely to be threatened.

Organizations that have undertaken resource management training programs report that after exposure to this training, peer pressure often facilitates change among those individuals initially unreceptive to the program. At present, training approaches are entirely non-punitive, but some have suggested that the same standard should be 
applied to interpersonal competence as is now applied to technical competence. This, of course, implies a wholesale reevaluation of government and industry practices in the training and checking areas. Since these training programs are only beginning to be implemented, and only by a few airlines, we do not know whether they will produce any meaningful or long-lasting benefits. Nonetheless, it would be foolhardy to suggest that better knowledge of these issues, and efforts to provide this knowledge to those who stand to gain, are not a step in the right direction. 


\section{REFERENCES}

Bales, R. F. Interaction process analysis: Theory, research, and application. Reading, Mass: Addison-Wesley, 1950.

Blake, R. R., \& Mouton, J. S. The new managerial grid. Houston: Gulf, 1978.

Cooper, G. E., White, M. D., \& Lauber, J. K. (Eds.) Resource management on the flight deck (NASA CP-2120). Moffett Field, CA: NASA-Ames Research Center, June, 1979. (NTIS No. N80-22283)

Duval, S., \& Wicklund, R. A. A theory of objective self awareness. New York: Academic Press, 1972.

Fiedler, F. E. A theory of leadership effectiveness. New York: McGraw-Hill, 1967.

Foushee, H. C. The role of communications, socio-psychological, and personality factors in the maintenance of crew coordination. Aviation, Space, and Environmental Medicine, 1982, 59, 1062-1066.

Foushee, H. C., \& Manos, K. L. Information transfer within the cockpit: Problems in intracockpit communications. In C. E. Billings \& E. S. Cheaney (Eds.), Information transfer problems in the aviation system (NASA TP-1875). Moffett Field, CA: NASA-Ames Research Center, September, 1981. (NTIS No. N81-31162)

Hackman, J. R., \& Morris, C. G. Group tasks, group interaction process, and group performance effectiveness: $A$ review and proposed integration. In L. Berkowitz (Ed.), Advances in experimental social psychology (Vol 8). New York: Academic Press, 1975.

Hare, A. P. Bibliography of small group research: 1959-1969. Sociometry, 1972, 95, 1150.

Harper, C. R., Kidera, G. J., \& Cullen, J. F. Study of simulated airline pilot incapacitation: Phase II, subtle or partial loss of function. Aerospace Medicine, $1971,\{2,946-948$.

Helmreich, R. L. Applied social psychology: The unfulfilled promise. Personality and Social Psychology Bulletin, 1975, 1, 548-561.

Helmreich, R. L. Pilot selection and training. Paper presented at the meeting of the American Psychological Association, Washington, D. C., August, 1982.

Janis, I. L. Victims of groupthink: A psychological study of foreign policy decisions and fiascos. Boston: Houghton, 1972.

Jones, M. B. Regressing group on individual effectiveness. Organization Behavior and Human Performance, 1974, 11, 426-451. 
Lanzetta, J. T., \& Roby, T. B. The relationship between certain group process variables and group problem-solving efficiency. Journal of Social Psychology, 1960, 52, 135148.

Lauber, J. K., \& Foushee, H. C. Guidelines for line-oriented flight training (Vol. 1, NASA CP-2184). Moffett Field, CA: NASA-Ames Research Center, August, 1981. (NTIS No. N81-30101)

Mark, R. A. Parameters of normal family communication in the dyad. Unpublished doctoral dissertation, Michigan State University, 1970.

McGrath, J. E., \& Altman, I. Small group research: A synthesis and critique of the field. New York: Holt, 1966.

National Transportation Safety Board. Aircraft accident report (NTSB-AAR-79-2). Washington, D. C.: NTSB Bureau of Accident Investigation, February, 1979(a). (NTIS No. UB-E-104-002)

National Transportation Safety Board. Aircraft accident report (NTSB-AAR-79-7). Washington, D. C.: NTSB Bureau of Accident Investigation, June, 1979(b). (NTIS No. N80-11051)

National Transportation Safety Board. Aircraft accident report (NTSB-AAR-80-1). Washington, D. C.: NTSB Bureau of Accident Investigation, January, 1980. (NTIS No. PB80-910408)

National Transportation Safety Board. Aircraft accident report (NTSB-AAR-82-8). Washington, D. C.: NTSB Bureau of Accident Investigation, August, 1982. (NTIS No. PB82-910408)

Ruffell Smith, H. P. A simulator study of the interaction of pilot workload with errors, vigilance, and decisions (NASA TM-78482). Moffett Field, CA: NASA-Ames Research Center, January, 1979. (NTIS No. N79-14769)

Spence, J. T., \& Helmreich, R. L. Masculinity and femininity: Their psychological dimensions, correlates, and antecedents. Austin, TX: Univ. of Texas Press, 1978.

Steiner, I. D. Group process and productivity. New York: Academic Press, 1972.

Webster's new collegiate dictionary. Springfield, Mass.: Merriam, 1961.

Wolfe, T. The right stuff. New York: Farrar, Straus, \& Giroux, 1979. 